\title{
Políticas sociales chilenas entre 2000-2010. La dualidad pobreza / desigualdad como objeto de política social
}

\author{
Chilean social policies between 2000-2010. The duality of poverty/inequality as the \\ object of social policy
}

Valeria Sánchez

\section{Introducción}

La equidad es una noción que ha prevalecido, promovida por diversos organismos internacionales de nivel global y regional, para orientar las políticas sociales. Su entendimiento depende del concepto de justicia, del derecho, de las leyes, por tanto su interpretación dependerá de los valores, las tradiciones y la ética de una sociedad determinada. Es un término que puede ser abordado desde la perspectiva filosófica, valorativa o jurídica, y aplicado al campo de los derechos humanos, la ciudadanía, o la economía.

La equidad ha sido un término ampliamente utilizado en políticas de salud en diversos países (Le Grand, 1987; Culyer y Wagstaff, 1992). Algunos autores problematizan el hecho de que se utilice la equidad como sinónimo de igualdad, e intentan abordar esta confusión haciendo la distinción entre ambos, situando al primero como un concepto normativo, mientras que le otorgan al segundo un carácter descriptivo (Le Grand, 1987). Para otros, el concepto de equidad alude a la cualidad que mueve a dar a cada uno lo que se "merece" y se asocia a la existencia de un piso mínimo de subsistencia considerado digno; mientras que la igualdad refiere a las distancias entre distintas categorías sociales en términos de poder y recursos, por tanto considera aspectos distributivos (Garretón y Cumsille, 2000). Existen textos que vinculan la equidad con los fundamentos éticos de una sociedad democrática y refieren a aquella noción para apelar a ciertos principios que deben orientar a la política social, tales como, la universalidad, la solidaridad y la eficiencia.

En Chile, desde la recuperación de la democracia en el año 1990, los gobiernos de centro izquierda que accedieron al poder se plantearon una estrategia de desarrollo denominada "crecimiento con equidad". Se mantuvieron los rasgos centrales del modelo de desarrollo del período dictatorial, centrado en un crecimiento económico basado en la

*Dirección de correspondencia [Correspondence address]: Valeria Sánchez, Universidad de Chile

E-mail: valeriasanchez@ug.uchile.cl extracción y exportación de recursos naturales, con una baja carga tributaria; se fortalecieron las instancias de regulación estatal y, paralelamente, se impulsaron políticas orientadas a aliviar a la población más carenciada. Las políticas sociales se propusieron minimizar la proporción de las personas que vivían bajo ciertos pisos básicos de bienestar por debajo de los cuales las condiciones de vida se estiman socialmente inaceptables. Dichas políticas probaron ser altamente exitosas en cierto sentido, considerando la fuerte reducción de la pobreza en el período. Sus énfasis estuvieron puestos en una alta focalización social, en el otorgamiento de subsidios y en promover el acceso a salud, educación, vivienda, de los grupos que hasta ese momento habían estado excluidos (Raczynski, 2008).

El objetivo de esta investigación es analizar la percepción de la dualidad pobreza / desigualdad como objeto de política social, en relación a aquellos actores de la época que tuvieron roles claves en ellas. Se busca cubrir el ciclo completo de las políticas públicas, desde la incorporación de los problemas que abordan en la agenda pública, su diseño a través de instrumentos de políticas, su implementación y ejecución en niveles locales, así como su evaluación y análisis ex post. Se entrevistó a personas cercanas al ejercicio de poder (asesores políticos de primer nivel, ministros); personas que conducen, diseñan las políticas sociales (ministros del área social, directores ejecutivos del área social); personas expertas en política social (funcionarios de organismos internacionales, académicos); personas que participan directamente en la ejecución y en la evaluación de ésta (alcaldes, consultores, miembros de fundaciones). La investigación se concentra en analizar específicamente el período que va desde el año 2000 al 2010, que corresponde a los gobiernos concertacionistas liderados por los ex presidentes R. Lagos (2000-2006) y M. Bachelet (2006-2010).

La aproximación metodológica al objeto de investigación es de carácter cualitativa, ello se fundamenta en que lo que se estudia se encuentra en el orden del sentido subjetivo, consciente o inconsciente, que la dualidad pobreza / desigualdad adquiere para los actores claves de las políticas. El análisis de discurso provee de los aportes teóricos e instrumentales que permiten indagar en la com- 
prensión significativa que tal objeto tiene para el colectivo investigado. Posibilita acceder a las visiones que orientan y estructuran, de manera manifiesta o latente, sus prácticas de políticas, es decir conocer cuál es la programación desde la que actúan los diversos actores. Para tales efectos se recurre a fuentes de información secundaria: análisis de documentos y textos de la época; y primaria: entrevistas en profundidad, aplicadas a perfiles de entrevistados definidos en función de criterios previamente establecidos.

\section{Resultados}

\section{Figuras típicas de la dualidad pobre- za / desigualdad y sus posiciones de habla}

El discurso en torno a la dualidad se estructura en cuatro posiciones de habla, las que refieren a las distintas ubicaciones desde las que se aborda el problema y que entran en interacción en el juego de relación que conforman los actores involucrados en tales políticas. Es importante precisar que las distintas posiciones de habla aluden a la perspectiva o racionalidad particular desde la que el asunto de la dualidad es problematizado. Ello no implica necesariamente que los entrevistados que apelan a cada posición tengan opiniones unánimes respecto de la materia que se está tratando en ella. En relación a tal asunto pueden existir valoraciones diferentes de personas que hablan desde una determinada ubicación, lo que se destaca en el análisis es el encuadre y/o programación desde la que aquel es abordado, razón por la cual el énfasis está puesto en ellas, más que en la opinión o valoración que de ellas hagan los entrevistados. De cada una de esas posiciones surgen cuatro figuras típicas, que constituyen las formas más expresivas y problemáticas del asunto que se investiga, las que organizan y articulan las diferentes aproximaciones a éste. La presentación de los resultados apelando a figuras que están presentes en el relato de los entrevistados, se debe a que éstas constituyen metáforas que logran condensar de manera sintética y elocuente los principales aspectos del problema que plantea la respectiva posición. Se trata de un recurso gráfico que da cuenta de la manera en que cada una de ellas dibuja o perfila la dualidad, así como de las estrategias u operaciones a que se recurre para intentar resolver tal tensión y/o contradicción. A su vez estas imágenes son producto del encuadre o racionalidad imperante en la posición correspondiente, representando ésta una lógica particular con la que se aborda el problema. Este lente o enmarque es una aproximación al asun- to a partir de una visión particular, lo que da como resultado una programación articulada y coherente desde la que aquel se observa. Este programa no es necesariamente consciente para aquellos que lo sustentan, sin embargo resulta determinante en su manera de aproximarse y comprender la cuestión que se investiga (Águila y Montoro, 1984 citado en García Ferrando e Ibáñez, 2000).

El análisis del material que proveen las entrevistas, arroja como producto la estructura del discurso que sobre el objeto de estudio tiene el colectivo investigado. Como resultado de tal proceso se identifica una estructura constituida por cuatro figuras en torno a la dualidad pobreza / desigualdad, las que corresponden a cada una de las posiciones de habla que emergen de las entrevistas, las que se detallan a continuación:

1. El habla del poder-gobernabilidad, que concibe y administra la dualidad como un asunto de equilibrismo entre objetivos en tensión: crecimiento económico?reducción de la pobreza asociados a estabilidad versus reducción de la desigualdad asociado a alteración del orden. La operación de equilibrismo apunta al ejercicio de acoger cierto imaginario social en torno a la igualdad, al mismo tiempo que evitar cualquier movimiento que ponga en cuestión la estructura y ordenamiento básico establecido.

2. El habla del hacer-pragmático, en que la dualidad toma la forma de una transacción entre encuadres de ideas disímiles en disputa: el paradigma neoliberal heredado versus el bienestarista que proviene de visiones socialdemócratas o socio-liberales. Esta racionalidad pragmática opera con la lógica de la transacción: busca avanzar en políticas más progresistas "en la medida de lo posible", asumiendo ciertos elementos del modelo basado en el Estado de Bienestar, a cambio de dejar fuera componentes sustantivos, como la universalidad.

3. El habla del saber-instrumental, que figura la dualidad como un ocultamiento, contrapone dos campos del conocimiento, visualizados con diverso nivel de valoración: el reconocido ámbito económico técnico que responde al paradigma de la eficiencia versus el político e ideológico, que se concibe menoscabado. La operación de ocultamiento apunta a una instrumentalización del conocimiento que busca invisibilizar los sesgos ideológicos de las opciones de políticas otorgándoles un carácter aparentemente neutro y/o tecnocrático.

4. El habla de la experiencia-invisible que apela a la figura de la fragmentación para dar cuenta 
de una escisión de las diversas dimensiones de los problemas de pobreza y desigualdad: las de carácter material, individual y homogéneo que son objeto de la política social versus las de tipo relacional, colectivo y heterogéneo en función de la diversidad territorial, que están ausentes de ella. La fragmentación apunta a una operación de separación, que divide los problemas dejando fuera aspectos fundamentales, excluyendo de las políticas algunos de sus componentes claves.

\section{Conclusiones}

\section{La estructura dual del discurso en torno a la dualidad pobreza / de- sigualdad}

Las distintas posiciones de habla están vinculadas principalmente al rol que dichos actores claves han ejercido en la política pública y a su trayectoria política y/o profesional. El análisis del discurso en torno a aquella dualidad da lugar a una determinada estructura de sentidos, la que orienta las acciones de tales actores sobre la materia. Dicha estructura articula las distintas posiciones desde la que la dualidad es tratada y establece las relaciones que se construyen entre sí. Cada uno de los lugares desde donde se habla toma una ubicación respecto de los otros: no se trata de posicionamientos aislados, sino que cada cual funciona en relación a las demás, con mayores o menores puntos de coincidencia entre sí. Respecto del discurso que se estructura en relación al objeto de investigación, ha resultado relevante evidenciar las convergencias y divergencias respecto de los contenidos que desarrollan cada posición de habla, así como las percepciones mutuas que manifiestan.

Existe entre las primeras tres posiciones de habla (del poder-gobernabilidad, del hacer-pragmático y del saber-instrumental) un alto nivel de consonancia en sus argumentaciones, aun cuando cada una de ellas mantiene su especificidad en el abordaje de la dualidad. Las referencias mutuas entre estas aproximaciones se relacionan con las limitaciones que sus integrantes perciben de las demás: la del saber-instrumental y la del hacer pragmático son críticas de la posición de habla del podergobernabilidad, aluden a sectores políticos y autoridades con escasa preparación en las materias sociales que conducen. La posición de habla del saberinstrumental aparece ejerciendo influencia en la del poder-gobernabilidad y la del hacer pragmático; esta última comparte la misma percepción limitada respecto de la del poder gobernabilidad, respecto de la cual muestra cierta prescindencia. Al mismo tiempo, la posición de habla del hacer pragmático aduce limitaciones que le son impuestas a su gestión por parte de sectores del ejecutivo con una visión centrada en la eficiencia, propia de la posición de habla del saber-instrumental. A diferencia de las otras tres, la cuarta posición de habla -experiencia-invisible-, se muestra ajena al campo en que se desenvuelven las primeras. Esta última se coloca en interpelación respecto de las anteriores y elabora planteamientos que responden a una lógica que dista de la racionalidad que evidencian aquellas, como se verá a continuación.

Las tres primeras posiciones de habla aludidas hacen permanente referencia a los distintos encuadres transnacionales de ideas que orientan la política social de la época, tomando diferentes posturas ante ellos. La del hacer-pragmático lo plantea como un hecho que atañe y afecta directamente el desarrollo de las iniciativas que se llevan a cabo en el ámbito de la política social, constatando la disonancia entre un discurso bienestarista de derechos "foráneo" y una práctica e instrumentos de políticas "nacionales" de carácter subsidiario y de orientación neoliberal. Esta posición de habla se encuentra situada en una compleja ubicación que busca atenuar la mencionada disonancia, a través de vías subrepticias que le den un matiz más progresista a la política social dentro de las restricciones en que opera. El saber-instrumental, por su parte, reconoce la primacía del paradigma neoliberal imperante y de las políticas de orientación subsidiaria, justificándolo por su rendimiento en el crecimiento económico y en prevenir culturas de dependencia propias de regímenes bienestaristas, como los europeos. Mientras, la posición de habla del poder-gobernabilidad fundamenta la permanencia de aquel paradigma en que tal encuadre reditúa políticamente en términos de credibilidad económica internacional, estabilidad social y resguardo del orden socio económico.

Estos tres grupos de habla perciben la dualidad pobreza / desigualdad como un asunto de relevancia y de alta significación en el diseño de las políticas públicas, validando con su discurso la polaridad entre ambos términos. Desde sus aproximaciones, tal dualidad es un asunto vigente que genera tensiones aún no resueltas, en especial cuando ellas son analizadas desde una perspectiva de más largo plazo, en que las disonancias se habrían hecho más evidentes. Distante de aquellas posiciones de habla, se sitúa la de la experiencia invisible, pues para sus representantes, los encuadres transnacionales de ideas no resultan ser un eje central en su abordaje como lo es para las anteriores, no existe una presencia significativa de ellos en su discurso. A diferencia de las tres primeras, para la posición de 
habla "experiencia-invisible", la dualidad pobreza / desigualdad como tal no posee el nivel de resonancia que tiene para aquellas. Su ubicación desde la experiencia de los sujetos que vivencian tales problemas y desde el territorio en que ellos acontecen, hace captarlos desde una perspectiva particular. Los asuntos de pobreza y desigualdad en tanto objeto de política social, son percibidos por esta ubicación de habla no como una polaridad, sino como dos componentes interrelacionados de la misma cuestión. Esta lógica concibe la dualidad como una escisión al interior de los términos pobrezadesigualdad, en relación a las dimensiones que de éstos son consideradas y las que son invisibilizadas por la política social. Se trata de una mirada que se aproxima desde otra perspectiva a la cuestión examinada en esta investigación. Acentúa los aspectos que no son captados por las políticas, no obstante son muy relevantes para los destinatarios. Según ella, los componentes de los problemas de pobrezadesigualdad menos evidentes pero de alta relevancia, no existen para los tomadores de decisiones y para quienes desempeñan el papel de autoridades y expertos en tales materias. Es una posición que busca ser la voz de los sujetos de las políticas sociales, que no tienen habla para ellos y cuyos requerimientos más significativos están ausentes desde las otras racionalidades.

Dada la anterior constatación, la estructura del discurso sobre la dualidad toma a su vez una forma dual: por una parte, existen tres lógicas que articulan una conversación que se desarrolla en un campo con materias compartidas y significativas entre sí; por otra, está la posición de habla de la experienciainvisible, que aparece escindida del primer decir y desvinculada de su campo de conversación. Ello podría estar indicando que se trata de una modalidad de desarrollo de la política social que, por un lado, está muy referido al campo internacional, a las ideas en circulación en espacios que trascienden sus fronteras y, por otro, que se encuentra a nivel nacional encapsulada en campos restringidos a los expertos y a los tomadores de decisiones públicas. Asimismo, se trata de una política que evidencia escasos y casi nulos mecanismos de retroalimentación hacia aquellos niveles más cercanos a quienes son los sujetos destinatarios de ella. Esto daría cuenta de una separación entre las visiones que idean e impulsan las políticas, y otras visiones destinadas a ser receptores pasivos de ellas, así como una so- brevaloración de los conocimientos de los primeros y una subestimación de lo que los segundos pueden aportar a aquellas. Esta constatación se relaciona con las deudas pendientes del Estado chileno con procesos de descentralización y participación, unos que permitan que las decisiones de política pública sean tomadas en las instancias y espacios más

cercanos a quienes tales determinaciones afectarán.

La estructura del discurso descrita pone en evidencia el peso que toman las variables relativas al rol que desempeña el actor en la política social, así como su trayectoria profesional y/o política, en hacer converger sus aproximaciones. A diferencia de estas variables, la orientación doctrinaria aparece teniendo escasa influencia. La predominancia de la aproximación experta técnica centrada en la eficiencia se presenta transversalmente en los decisores, diseñadores y promotores de las políticas, incluso trasciende la orientación política-ideológica y, en ocasiones, también la formación profesional. Algo similar ocurre en la aproximación local -centrada en los problemas de segmentación y segregación-, crítica de aquella visión "experta": aquella se presenta de manera transversal, tanto en autoridades locales oficialistas ?de centro izquierda- como de oposición de la época ?de derecha-.

\section{Referencias}

Culyer, A. J. y Wagstaff, A. (1992). Need, equity and equality in health and health care. Discussion Paper, 95.

García Ferrando, M., A. F. e Ibáñez, J. (2000). El análisis de la realidad social. Alianza, Madrid.

Garretón, M. y Cumsille, G. (2000). Percepciones culturales de la desigualdad. Facultad de Ciencias Sociales, Universidad de Chile y Ministerio de Planificación y Cooperación, Santiago de Chile.

Le Grand, J. (1987). Equity, health and health care. Social Justice Research, 1(3):257-274.

Raczynski, D. (2008). Sistema Chille Solidario y la Política de Protección Social de Chile. CieplanInstituto F. Henrique Cardozo. 